\title{
SUSTENTABILIDADE CULTURAL: TECNOLOGIA A SERVIÇO DO ARTESANATO INDÍGENA
}

Bruno Vinícius Castro Guimarães ${ }^{1}$, Elias Brasilino de Souza ${ }^{2}$, Ana Maria Alves Abreu $^{3}$, Gabryella Castro Guimarães ${ }^{4}$, Maycon Murilo Castro Guimarães ${ }^{5}$

1 Professor Doutorando do Instituto Federal do Amazonas

(bvinicius20@yahoo.com.br) São Gabriel da Cachoeira, Amazonas-Brasil

2 Professor Mestre do Instituto Federal do Amazonas

3 Gerente de Serviços, Banco do Brasil S/A

4 Enfermeira Especialista do Instituto Federal do Amazonas São Gabriel da Cachoeira, Amazonas-Brasil

5 Engenheiro Agrônomo Mestre da Universidade Estadual do Sudoeste da Bahia

Recebido em: 08/04/2017 - Aprovado em: 10/06/2017 - Publicado em: 20/06/2017 DOI: 10.18677/EnciBio_2017A150

\section{RESUMO}

Este estudo teve como foco o artesanato, uma das mais ricas expressões da cultura de um povo. No caso do artesanato indígena da região do Alto rio Negro, a matériaprima é produzida e transformada manualmente. Esta prática é realizada predominantemente pelas mulheres indígenas, em todos os níveis do beneficiamento da fibra de tucum, fato que se traduz em baixo rendimento na produção dos artigos e produtos artesanais. Em face deste contexto, o presente trabalho teve por objetivo desenvolver mecanismos, acessórios e artefatos para otimizar o beneficiamento das fibras de tucum e propiciar melhor rendimento na produção do artesanato indígena. $\mathrm{O}$ projeto foi implantado no Instituto Federal do Amazonas, Campus São Gabriel da Cachoeira. A proposta de capacitação contemplou cinco associações indígenas. Os modelos de fiação semi-industrial, caracterizados como fiador de tucum à pedal com reversor (Tc-Pr) e o fiador de tucum motorizado com reversor (Tc-Mr), apresentaram maior produção de fios de tucum em relação ao artesanato tradicional. O mecanismo Tc-Pr à pedal, indicado para as comunidades sem energia elétrica, pode chegar à produção de 40 metros de fio de tucum em oito horas de trabalho, enquanto que o instrumento Tc-Mr, pode produzir até 200 metros de fio no mesmo período. A partir da matéria-prima utilizada, a produção tornou-se mais dinâmica, com o uso de uma tecnologia social a serviço da cultura indígena. Além disso, a tecnologia provocou maior competitividade quanto aos preços, à quantidade e à qualidade dos artesanatos da espécie utilizada, acelerando-se o processo produtivo em todas as etapas.

PALAVRAS-CHAVE: Design, Fibra de Palmeira, Florestal Têxtil, Produto, Tecnologia.

\section{CULTURAL SUSTAINABILITY: TECHNOLOGY AT THE SERVICE OF INDIAN CRAFT}

\section{ABSTRACT}

This study focuses on the craft as one of the richest expressions of the culture of a people. In the case of crafts Indian of the Upper Rio Negro region, the raw material is 
produced and processed entirely manually and this practice is realized predominantly by women indigenous people, in all processing levels of tucum fiber, a fact that translates into low performance from handmade product. Given this context, this study has the objective to develop mechanisms, accessories and artifacts to optimize the processing of tucum fibers and provide a better performance in the production of craftworks Indians. The project was implemented at the Federal Institute of Amazonas, Campus St. Gabriel Cachoeira. The proposed training contemplated five indigenous associations. The models of semi-industrial wiring, characterized as guarantor tucum the pedal with reverser (Tc-Pr) and motorized tucum guarantor with reverser (Tc-Mr), showed significant production tucum wires compared to traditional crafts. The Tc-Pr mechanism pedal, suitable for communities without electricity, can reach production of 40 meters tucum wire in 8 hours, while the Tc-Mr instrument can produce up to 200 meters of wires in the same period. From the raw material used, the most dynamic production with the use of social technology at the service of indigenous culture. In addition, the technology has caused more competitive as to price, quantity and quality of crafts of species used, speeding up the production process at each processing stage.

KEYWORDS: Design, Palm Fiber, Forest Textile Product, Technology

\section{INTRODUÇÃO}

O artesanato Brasileiro constitui um segmento produtivo da economia cujo crescimento possui alto potencial de geração de trabalho e renda (MDIC, 2017). Tal ocorrência se dá frente a um conjunto de circunstâncias na qual se depara com o desafio de obter novos materiais que sejam produzidos a partir de fontes renováveis de matérias-primas, no âmbito tecnológico da produção têxtil (CARDOSO \& GONÇALEZ, 2016).

Como reforço de materiais plásticos, as fibras vegetais apresentam algumas vantagens em relação às fibras sintéticas. Isso se evidencia pela abundância e variedade de plantas fibrosas disponíveis na biodiversidade, enquanto fontes de recursos renováveis, além do baixo custo relacionado à extração destas, incluindo o fato de serem biodegradáveis e possuírem baixa densidade (ALBINANTE et al.,, 2013).

A imensa variedade de plantas fibrosas da flora tropical amazônica (PALMweb, 2016), associada ao vasto conhecimento popular de utilização das fibras vegetais, sugere a possibilidade de transformação dessas matérias-primas em plantas cultiváveis para o desenvolvimento de produtos com denominação de origem, com alcance de benefício social, cultural, ambiental, tecnológica e econômica para a região. Dadas estas condições, a biodiversidade do ecossistema amazônico constitui um amplo potencial natural do mundo contemporâneo, servindo como material para estudo científico e insumo a ser destinado as bioindústrias (SOENTGENA \& HILBERTB, 2016).

As fibras vegetais, por serem abundantes, de baixo impacto ambiental e oferecerem propriedades tecnológicas adequadas às aplicações na indústria, estão se tornando alternativas atrativas, numa perspectiva econômica e sustentável. Razão pela qual esse segmento produtivo vem aumentando, a partir dos avanços nas pesquisas orientadas quanto à sua utilização e aplicação (GUIMARÃES et al., 2010). O crescente interesse pelo conhecimento acerca das estruturas constitutivas das fibras e propriedades vegetais, os quais auxiliam na confecção de novos produtos e de novas aplicações, mostra-se cada vez mais em evidência tanto para o âmbito científico como para o campo mercadológico (PACHECO et al., 2011). 
No segmento de fibras naturais provenientes das palmeiras, encontra-se a fibra do tucum, originada da espécie Astrocaryum acaule Mart., que segundo ABREU \& NUNES (2012), apresenta potencialidade econômica tanto no sistema foliar, quanto no endocarpo do fruto, ambos caracterizados pelas fibras de alta performance e resistência (DIDONET \& FERRAZ, 2014), utilizados para o desenvolvimento de produtos artesanais, tais como: bolsas, calçados, esteiras, tapetes, redes, colares, pulseiras, chapéus, entre outros. A sua distribuição geográfica está concentrada, em ampla parte, no estado do Amazonas, principalmente na área pertencente ao Alto rio Negro, onde a população indígena figura como maior fornecedora e consumidora dos artesanatos produzidos (FORTES et al., 2016). Os cuidados e a valorização da fibra do tucum se inicia no cultivo da palmeira. Nessa fase a fibra, matéria-prima, é definida. Para confecção em produtos, a extração da fibra tem destaque sobre as demais fases do processamento artesanal (ABREU \& NUNES, 2012).

Neste contexto, a matéria-prima é produzida e transformada de forma totalmente artesanal, sendo essa prática realizada predominantemente pelas mulheres indígenas, em todos os níveis do beneficiamento da fibra de tucum. Em tais condições de inexistência de instrumentos tecnológicos, o processo produtivo resulta em baixo rendimento na fabricação dos artigos e produtos artesanais (ABREU \& NUNES, 2012).

O artesanato é sinônimo de identidade cultural e uma das formas mais espontâneas de expressão do povo brasileiro. De acordo com a Comissão Consultiva do Artesanato, este pode ser definido como atividade predominantemente manual de produção de um bem que requeira criatividade e/ou habilidade pessoal, podendo ser utilizadas ferramentas e máquinas (TROMBINI, 2017). Sendo assim, considera-se algo muito oportuno adaptar a produção dos artigos indígenas, diretamente, ao processo semi-industrial - com 0 apoio de ferramentas, equipamentos e máquinas, que contemplem mecanismos para maximizar a produção dos artigos indígenas.

No Brasil, o Programa do Artesanato Brasileiro (PAB) está vinculado ao Ministério do Desenvolvimento, Indústria e Comércio Exterior (MDIC) e visa: fortalecer a competitividade do produto artesanal para a geração de trabalho e renda, além de promover acesso ao mercado externo, por meio da capacitação de artesãos e multiplicadores, feiras e eventos para a comercialização de produtos artesanais, e a estruturação produtiva do artesanato brasileiro (MARTINEZ et al., 2012).

PACHECO et al. (2011) asseveram que a pesquisa é, nesse caso, uma ferramenta importante que podem produzir reflexos de natureza política, econômica, sociocultural, tecnológica e ambiental. Pela ampla abrangência e implicações sobre as diversas dimensões, a gestão e o desenvolvimento de novos produtos competitivos não é uma tarefa fácil, devido a exigência do mercado que cobra esforço contínuo de renovação para aqueles que se acostumaram a produzir os mesmos produtos durante anos e que, por isso mesmo, precisam oferecê-los como inventos criativos e novos. É nestas condições que a pesquisa pode auxiliar na produção de informações, tomadas de decisões, solução de problemas e no suporte técnico-científico com dados relevantes para determinados fins.

Em face do exposto, vê-se que a atividade artesanal em São Gabriel da Cachoeira, Amazonas, constitui uma importante alternativa que pode propiciar redistribuição de renda, contribuindo para a melhoria das condições de vida da população envolvida. Nesse sentido que esse trabalho teve por objetivo buscar e 
desenvolver mecanismos, acessórios e artefatos para otimizar o beneficiamento das fibras de tucum e fortalecer o artesanato indígena, além de identificar as oportunidades e limitações do uso semi-industrial que a matéria-prima poderá oferecer em função das necessidades de mercado, tipos de produtos, dos benefícios às comunidades produtoras, do respeito à cultura local e ao meio ambiente, consideradas as demandas do público consumidor.

\section{MATERIAL E MÉTODOS}

Foi implantado um projeto original para suporte e aperfeiçoamento do artesanato indígena com foco na inovação e desenvolvimento tecnológico da produção artesanal por meio da matéria-prima fibra de tucum. O curso de qualificação artesanal intitulado sustentabilidade cultural: tecnologia a serviço do artesanato indígena foi desenvolvido no Instituto Federal do Amazonas/Programa Nacional de Acesso ao Ensino Técnico e Emprego - PRONATEC, Campus São Gabriel da Cachoeira, no período de 21 de outubro a 20 de novembro de 2014.

A capacitação contemplou as cinco principais associações de produtores tradicionais indígenas de artesanato na região do Alto rio Negro - Associação Arte Puranga Indígena do Rio Negro - AAPIRN; Associação dos Artesãos Indígenas ASSAI; Assunção - AMIB; Pari-cachoeira; Yauaretê e Taracuá, perfazendo a capacitação de 30 profissionais, exclusivamente mulheres indígenas entre 18 e 60 anos. As participantes foram indicadas pelas associações, sendo que a essência da capacitação é a geração, produção e multiplicação do conhecimento por meio de eventos e oficinas nas comunidades de origem.

No intuito de minimizar o custo de produção da matéria-prima, fio de tucum, promover maior eficiência e otimizar a produção artesanal, foram desenvolvidos artefatos de fiação da fibra do tucum em duas versões - fiador de tucum à pedal com reversor (Tc-Pr) e o fiador de tucum motorizado com reversor (Tc-Mr) (Figura 1). Além disso, foram fabricados teares à pedal e de pente-liço, para confecção e acabamento das unidades artesanais ${ }^{1}$ (Figura 2).
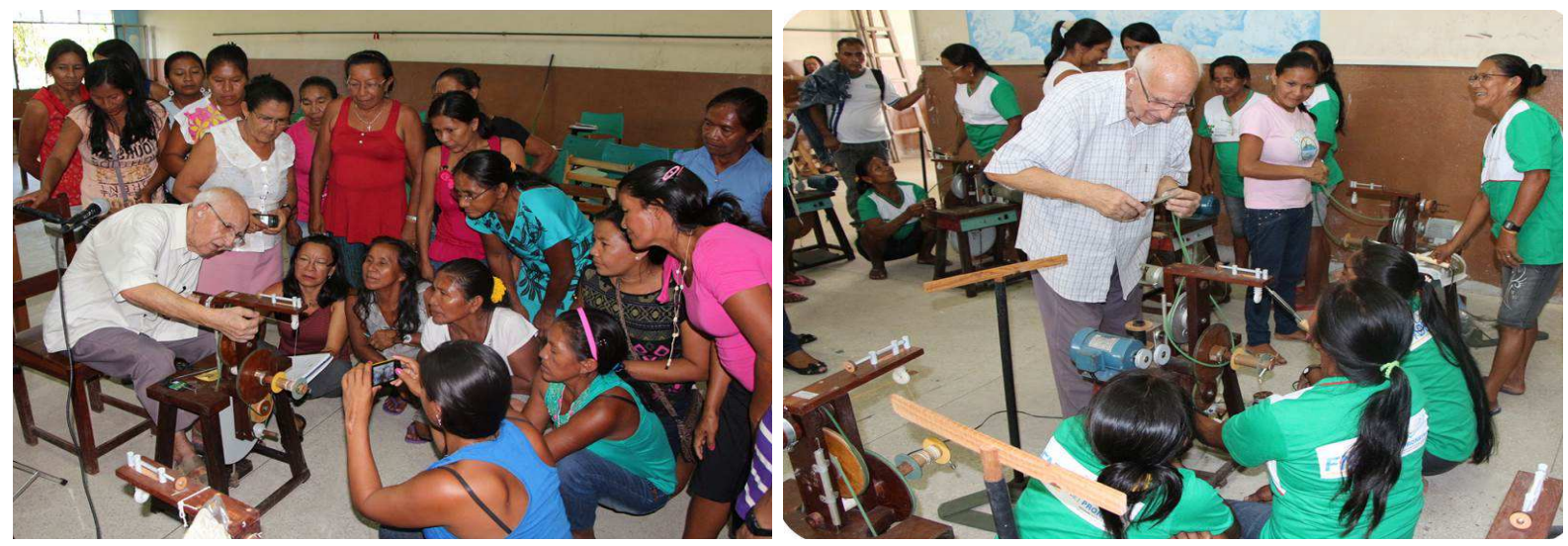

FIGURA 1 Demonstração do fiador de tucum à pedal com reversor (Tc-Pr) e o fiador de tucum motorizado com reversor (Tc-Mr)

Foto: Bruno Guimarães, (2014).

\footnotetext{
${ }^{1}$ As tecnologias sociais referidas nesse trabalho, tendo-se em vista o cumprimento do objetivo proposto, foram confeccionadas pelo missionário salesiano, Pe. Bruno Bianchi, parceiro fundamental para a implementação da proposta aqui apresentada.
} 


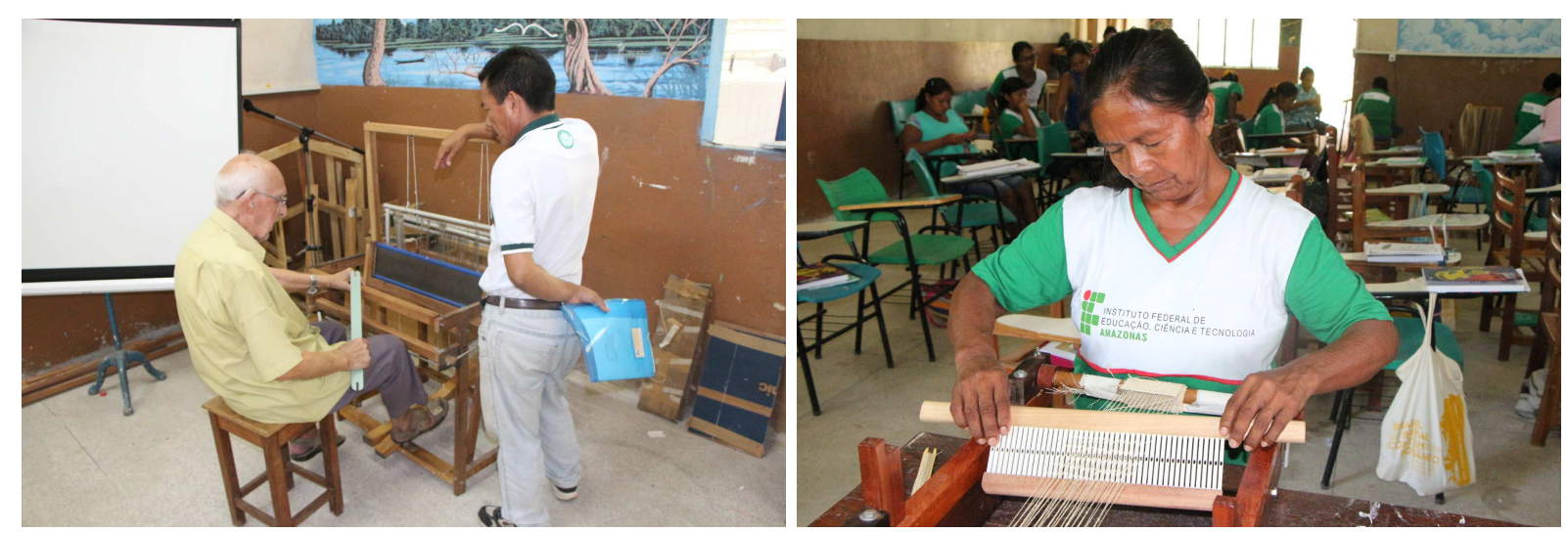

FIGURA 2 Teares à pedal à esquerda e de pente-liço à direita

Foto: Bruno Guimarães, (2014).

Os artefatos Tc-Pr e Tc-Mr é o resultado de inúmeros ensaios experimentais desenvolvidos no decorrer de 5 anos pelo Pe. Bruno Bianchi, com a finalidade de ajustar, desenvolver e idealizar um mecanismo que pudesse maximizar a receita familiar indígena por meio da produção sustentável de artesanatos, com uso da fibra tucum. Além disso, com o guia prático e o manual de fabricação, esses artefatos também puderam ser reproduzidos nas oficinas das comunidades interessadas.

Esse instrumento é um artefato prevalentemente de madeira, com rolimãs nos eixos, e dimensões bastante reduzidas, a saber: altura de $80,5 \mathrm{~cm}$; largura de $40 \mathrm{~cm}$ e cumprimento de $58 \mathrm{~cm}$; e aproximadamente $20 \mathrm{~kg}$.

$\mathrm{O}$ artefato intitulado Tc-Mr, versão motorizada, é composto por dois blocos: o conjunto motor fornece os movimentos de alta velocidade para fiação e retorção e o de baixa velocidade para a coleta do produto na bobina. O conjunto de fiação, apresenta duas funções, a primeira é articulada para unir as fibras têxteis numa linha só, e a segunda para reforçar o fiado com dois terminais entrelaçados, denominado retorção bifilar. Estas duas funções geram dois tipos de fio para diversas aplicações artesanais.

Considerando a completa formação e qualificação das artesãs indígenas, o curso contemplou instruções amplificadas - desde a produção de mudas de tucum até o beneficiamento, comercialização da fibra e confecção das biojóias. Nestes moldes, o treinamento foi apresentado com base nos seguintes itens:

Características da produção, conservação e extração das fibras de tucum Astrocaryum acaule Mart.; Propriedades da fibra de tucum; Uso da fibra bruta no desenvolvimento de design; Trabalhos de crochê, de malha e tecidos entrelaçados à mão; Tecidos de tear, urdido e trama; Conhecimento do manual de instruções: Formação do pavio mais uniforme possível, por meio do uso do suporte; Uso do pedal como motor; União de um pavio no outro dando continuidade ao fiado; Acompanhamento do pavio em fiação para evitar o balão e torções secundárias; Título do fio singelo; Conhecimento das relações de velocidade na torção do fio; Uso da máquina e demais equipamentos motorizados; Uso do pedal e painel elétrico, fusível, chave de pedal, reversão da rotação; Prevenção de acidentes; Torção secundária; Montagem das peças para fiação; Montagem das peças para retorção e rotação invertida; Acessórios; Apresentação e conhecimento das peças: Policorde; Reparo das correias (experiências práticas); Técnicas de manutenção e conservação das máquinas; 


\section{Etapas do treinamento}

No treinamento artesanal, as etapas de produção semi-industrial foram definidas nas seguintes linhas de produção: Extração e conservação das fibras de tucum; Uso da fibra bruta no desenvolvimento de design; Trabalhos de crochê, de malha e tecidos entrelaçados à mão; Tecidos de tear, urdido e trama; Descrição do manual de instruções; Conhecimento das relações de velocidade na torção; Uso da máquina e demais equipamentos motorizados; Uso do pedal e painel elétrico, fusível, chave de pedal, reversão da rotação; Montagem das peças para fiação; Acessórios; Apresentação e conhecimento das peças; Policorde; Reparo das correias; Conservação da máquina; Entrega dos manuais.

\section{Mecanismos de transmissão de movimentos}

A movimentação, na edição à pedal, Tc-Pr, é fornecida por um pedal de peça única, postado entre as colunas da base, articulado com a biela, que aciona a manivela montada diretamente no volante, cujo eixo roda sobre rolamentos embutidos nas colunas de madeira. Na edição motorizada, Tc-Mr, a movimentação é fornecida por um pequeno motor elétrico de $1 / 4 \mathrm{CV}(180 \mathrm{~W})$ com polias e pedal adaptados.

\section{0 volante, com o seu eixo}

Esse mecanismo movimenta as duas polias motoras, das quais, a maior é multiplicadora e produz a alta velocidade do torcedor. A polia acoplada subjacente ao volante é redutora, situada na parte traseira do mesmo eixo, esta produz a velocidade, necessária para a bobinação, proporcional ao fio torcido, e transmite o movimento à bobina que recolhe o fio singelo, acabado.

\section{Fiação}

O rotor torcedor é constituído por um cabeçote removível, montado sobre um eixo perfurado, deslizante sobre rolamentos embutidos nas colunas, e sobressalente delas. Este rotor é feito de madeira maciça, fornecida, na parte dianteira por dois pequenos braços sobre os quais estão montados quatro anéis metálicos, dirigidos para o centro, onde passarão as fibras em fase de torcedura para a fiação, na velocidade máxima de 700 RPM (rotações por minuto).

\section{$\mathrm{Tc}-\mathrm{Pr}$}

Neste modelo a operadora, posicionada em frente ao artefato, retira de um feixe, um número de fibras correspondentes à bitola do fio desejado (título) e as introduz em dois anéis opostos do torcedor. Acrescenta-se as fibras na medida em que o fio avança. Deve-se monitorar a torcedura com o movimento dos dedos para evitar sobreposição ou inversão oposta do fio. O fio produzido, e em torção, passa por um anel de nylon e se enrola na bobina montada no eixo traseiro. Esta pode ser removida e substituída facilmente pelo operador, conforme a necessidade.

\section{A operadora}

Com ambos os pés, a operadora, movimenta o pedal, alternativamente, após ter determinado com a mão o sentido de rotação desejado, que deverá ser sempre o mesmo para a direita.

\section{Velocidade}


A velocidade do cabeçote torcedor será sempre proporcional à da bobina, tanto no Tc-Pr, à pedal, quanto no Tc-Mr, motorizado, tendo presente que, para uma boa resistência do fiado, a espiral determinada pela torcedura do fio, deverá ser de $25^{\circ}$ de inclinação, sobre o eixo vertical do fio.

\section{Os eixos em rotação}

Os eixos em rotação são sustentados na plataforma maciça com as seguintes dimensões: $40 \times 25 \times 3 \mathrm{~cm}$. Montada sobre quatro pernas ligeiramente abertas na direção da base. Nesta plataforma estão encaixadas as colunas de sustentação que suportam os eixos do artefato, todos eles montados em rolamentos de esferas.

\section{Tc-Mr - versão motorizada}

Com as devidas modificações, o pedal neste modelo, é usado somente para iniciar e parar o movimento do motor. Para seu controle esta máquina usa um painel elétrico apropriado. É importante realçar que esta versão imprime no cabeçote 3600 RPM, o que exige muitos cuidados e atenção no treinamento. Na opção Tc-Mr a máquina deve ser conectada à linha elétrica de $110 \mathrm{~V}$. Caso não funcione adequadamente é necessário verificar o fusível no painel de controle.

\section{A retorção bifilar}

Pela simples permuta do cabeçote de torção com o cabeçote bifilar e da polia de bobinação, com a respectiva correia, tanto no mecanismo Tc-Pr como no Tc-Mr, promove-se a retorção bifilar. Nesse caso, ao inverter o sentido da rotação, realizase a torcedura dos dois fios, com a produção bifilar.

\section{RESULTADOS E DISCUSSÃO}

A produção de fio de tucum destaca-se em relação às demais palmeiras amazônicas por apresentar características que permitam a manipulação e extração do linho foliar (ABREU \& NUNES, 2012). Sendo essa fonte vegetal imprescindível na confecção de utensílios funcionais na arte da caça e pesca, bem como nos adereços de proteção e utilidade, faz-se necessário a fabricação diária do fio de tucum. Neste contexto, a produção da atividade artesanal mulher ${ }^{-1}$ dia $^{-1}$ alcança rendimento médio da confecção do fio de tucum de 8 metros de cumprimento. Sendo que, por ser uma técnica exclusivamente dotada dos recursos manuais, dificilmente se estabelece a padronização do diâmetro do fio de tucum produzido.

$\mathrm{Na}$ modalidade do artesanato tradicional, prática intrínseca à cultura indígena local, as etapas estabelecem um modo peculiar e são realizadas de forma totalmente manual, dispondo apenas de instrumentos domésticos produzidos pelas próprias comunidades. No âmbito da região aqui em foco, a cadeia produtiva do artesanato indígena contempla as seguintes etapas: seleção da palmeira, técnica de corte, lavagem e secagem, aplicação de tingimento natural, fixação da cor, amarração das ramas, técnica de fiação e, por fim, a tecelagem dos fios.

Esse trabalho buscou conciliar o desenvolvimento da fiação das fibras de tucum no viés artesanal, com a maior produção e a qualidade tradicional. A produção do fio de tucum, segundo a tradição indígena, é realizada mediante operação de torcer a fibra com a mão, esfregando-a sobre a coxa com uma manobra característica de vaivém. A produção do fio com esse sistema é muito limitado, revelando baixo rendimento de produção e inconstância no trabalho, pois a atividade artesanal promove lesões e, consequentemente, inflamações na pele da coxa das mulheres fiadeiras, fato que impossibilita 0 trabalho numa sequência 
quotidiana. Além disso, a operação somente é realizada nas horas que não haja sudoração na pele e o diâmetro do fio de tucum não pode ser fino em demasia, pois escorrega na ocasião da friç̧ão com a pele (Figura 3).

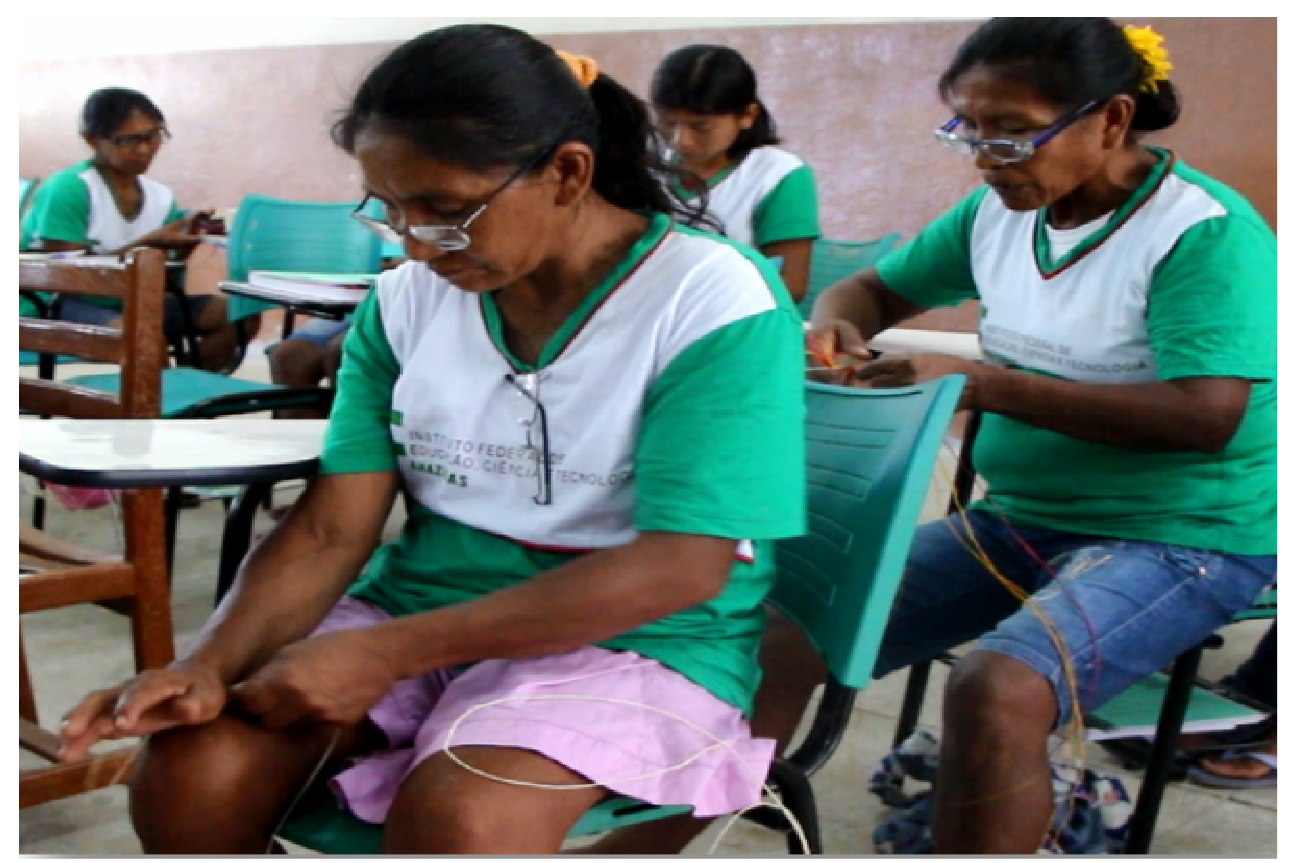

FIGURA 3 Produção tradicional de fio de tucum, no município de São Gabriel da Cachoeira/AM, durante capacitação de artesãs, em curso ofertado pelo IFAM - Campus São Gabriel

Foto: Bruno Guimarães, (2014).

Assim, diante da necessidade de promover o desenvolvimento do artesanato indígena, tornou-se imprescindível a aquisição e introdução de um mecanismo semiindustrial ou elemento artesanal, assegurando-se da não substituição e nem do não esquecimento dos saberes próprios do modo tradicional da cultura indígena local. Apenas associando uma simples tecnologia mecânica, com maior grau de eficiência na fiação do tucum, ao modo de fiação originário dos povos indígenas do Alto rio Negro.

Os modelos de fiação semi-industrial, caracterizados por Tc-Pr (Figura 4) e Tc-Mr (Figura 5), apresentaram significativa produção de fios de tucum, ao serem incorporados em caráter complementar ao modo de produção artesanal, mas sem comprometerem os saberes tradicionais já adquiridos anteriormente. O mecanismo Tc-Pr à pedal, mais adequado para utilização em comunidades indígenas sem acesso a serviços de energia elétrica, pode chegar à produção de 40 metros de fio de tucum em 8 horas de trabalho. Por outro lado, o modelo alternativo Tc-Mr, dotado de engrenagem motorizada, pode produzir até 200 metros de fio, no mesmo período. Ao passo que a produção exclusivamente manual representa $20 \%$ e $4 \%$, em relação aos mecanismos Tc-Pr e Tc-Mr, respectivamente (Figura 6). 


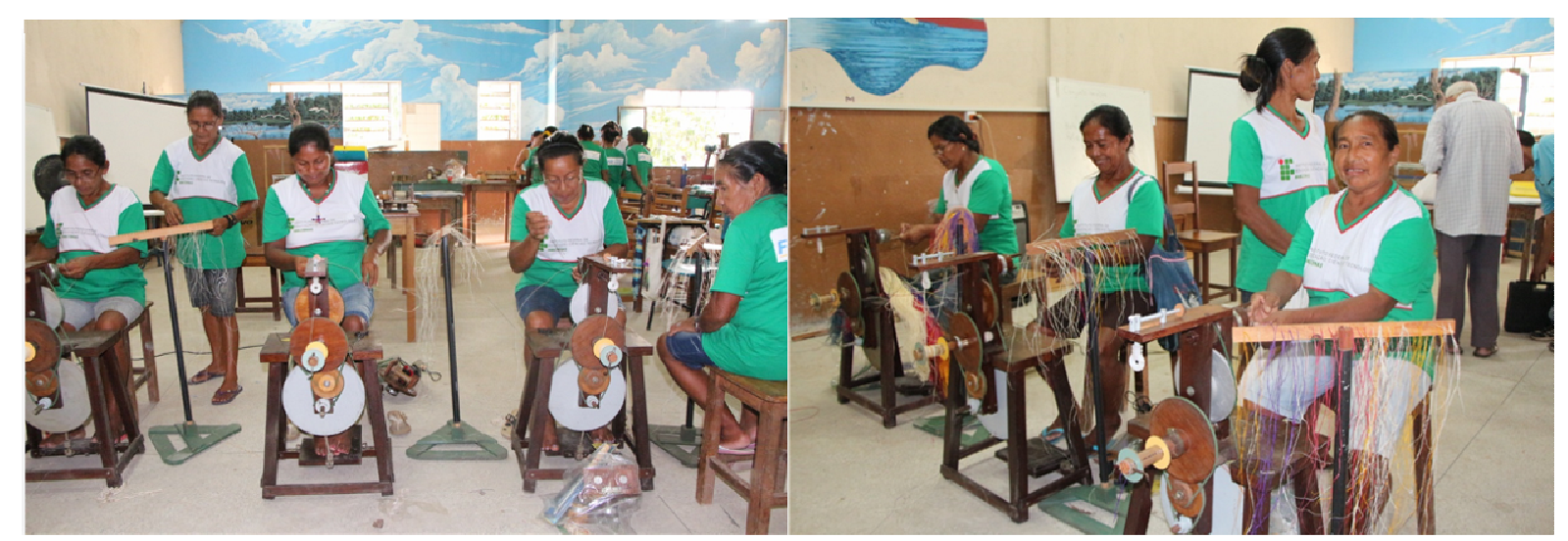

FIGURA 4 Fiador de tucum à pedal com FIGURA 5 Fiador de tucum motorizado reversor (Tc-Pr)

Foto: Bruno Guimarães, (2014). com reversor (Tc-Mr)

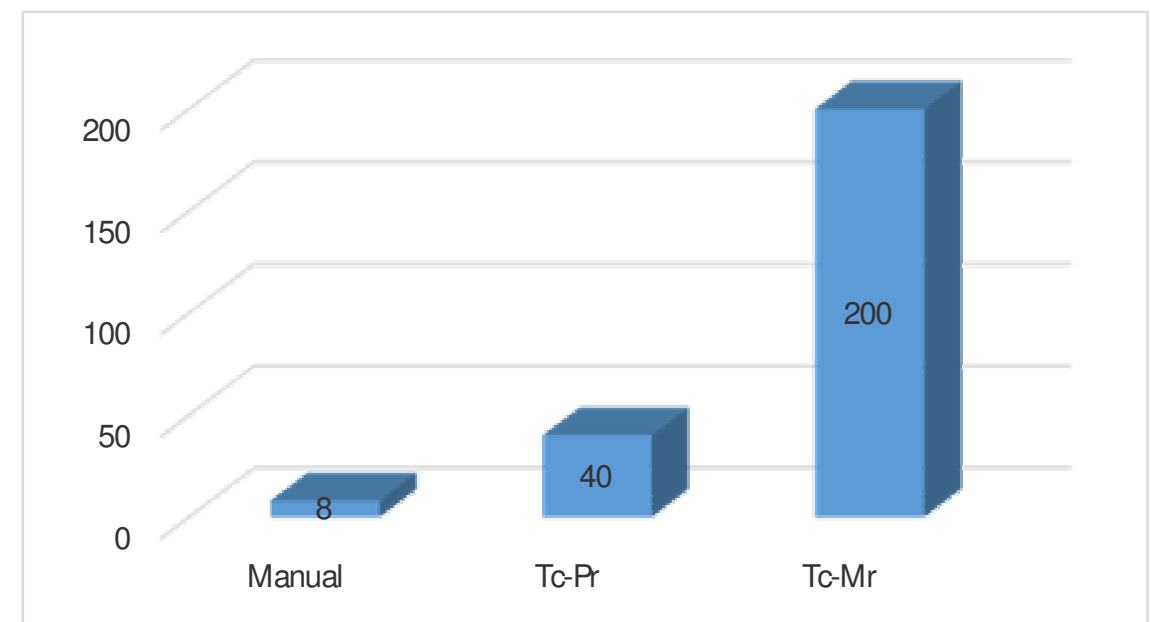

FIGURA 6 Sistemas de produção do fio de tucum, manual, Tc-Pr e Tc-Mr, representam, nesta ordem, a maior eficiência de produção.

Fonte: Dados primários da pesquisa, 2014.

No tocante ao desenvolvimento do projeto, verificou-se que as artesãs indígenas foram surpreendidas positivamente com o aspecto indissociável entre a arte de produção e a praticidade da execução em escala semi-industrial do fio de tucum. Neste aspecto, o conhecimento tradicional associado ao uso de máquinas, favorece a produção, padroniza a qualidade e assegura a originalidade do sistema indígena de produção do fio de tucum, fato que possibilita, com a produção satisfatória, a comercialização e exportação dos produtos, geração de emprego e renda, além de conscientizar as duas esferas do sistema de produção - artesão e consumidor; nesta ótica, os primeiros compreendem sobre a importância da produção sustentável, ao passo que os últimos, valorizam a originalidade da fibra, resistência e a condição biodegradável da matéria-prima, o que, consequentemente, minimiza riscos para o meio ambiente.

Neste propósito inovador e de natureza complementar, a produção de fios para a confecção dos artigos tradicionais indígenas, conta com a incorporação de tecnologias sociais de perfil semi-industrial, busca a valorização da natureza e o conhecimento tradicional capaz de transformar fibra de tucum em produto, de modo a alcançar novas economias e benefícios locais. Isso pode ser alcançado, sem ENCICLOPÉDIA BIOSFERA, Centro Científico Conhecer - Goiânia, v. 14 n.25; p.1923 2017 
precisar desvirtuar e nem descaracterizar os traços originais dos produtos, fabricados artesanalmente, além de fortalecer os valores, a tradição e a percepção da identidade cultural.

Nessa perspectiva, MAXIMIANO (2014) enfatiza que tais circunstâncias correspondem, simultaneamente, aos desafios e superação, pela busca de inovações e qualidade dos produtos para a concorrência. Isso deve ocorrer sem temor de dificuldades ou fracassos, relacionando a produção nas operações econômicas, bem como na organização, comercialização e gestão necessárias ao funcionamento do empreendimento.

PACHECO et al. (2011) ressaltam que a produção da fibra de tucum apresenta-se de acordo com as normas da Comissão Mundial sobre o Meio Ambiente, criada pela ONU, podendo ser considerada como um recurso natural capaz de suprir as necessidades atuais, sem comprometer as gerações futuras e de gerar emprego e melhores condições de vida para as comunidades produtoras. Todas as etapas vão agregando valores específicos às fibras produzidas pelo tucum, permitindo com que a utilização dessa matéria-prima se torne uma das principais fontes de renda sustentáveis da região amazônica.

\section{Valorização, negócios e mercado do artesanato indígena}

O artesanato é uma valiosa expressão das diversas culturas da humanidade, sendo uma representação histórica e comunitária, com dispersão temporal e espacial dessas características às gerações subsequentes. Pela característica artística, projetou-se numa atividade rentável, na geração de emprego e renda, com efeito positivo no desenvolvimento regional e na inclusão social (CERCHIARO, 2010).

O artesanato, no contexto indígena, reflete a história de diversas etnias, além de constituir alternativa de renda. Assim, o artesão, por meio do artesanato, representa as tradições, símbolos mágicos, encantos, cantos e crenças, expressos nos produtos confeccionados (SANTOS \& SILVA, 2016).

O artesanato nacional é intensamente motivado por diversas culturas europeia, africana e indígena. A diversidade e riqueza da fauna e sobretudo da flora, configura-se como a base da matéria-prima, que associada aos talentos culturais, obtêm-se produtos originais, atrativos e expressivos da cultura regional, valorizado em todo mundo.

No tocante à capacitação para confecção de artesanatos indígenas, tem-se em registro a proposta do Curso de Artesão de Artigos Indígenas, promovido pelo IFAM, Campus São Gabriel da Cachoeira, cujo público alvo foram as mulheres indígenas de diversas comunidades do Alto rio Negro e da Sede municipal. A implementação dessa iniciativa foi enriquecida com a participação direta do SEBRAE, que ministrou conteúdos com foco no empreendedorismo, plano de negócio e oportunidade de mercado para os artesãos indígenas (Figura 6 e 7) (SEBRAE, 2010).

Concernente à valorização dos ativos naturais disponíveis, OLIVEIRA et al. (2014) asseveram que a questão ecológica e a reciclagem dão também um novo impulso ao setor de produção artesanal, pois além de ser uma atividade tipicamente de baixo impacto ambiental, o reaproveitamento de materiais e o uso eficiente de recursos naturais não aproveitados em outras atividades, faz do artesanato indígena uma excelente forma de viabilizar projetos de sustentabilidade, seja por meio das organizações empresariais, seja pelos poderes públicos, através da formação de cooperativas e associações de artesãos. 


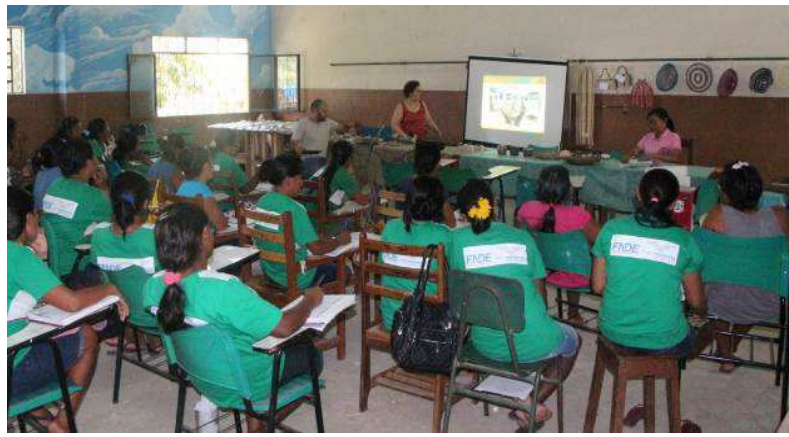

FIGURA 6 Treinamento com o SEBRAE

Foto: Bruno Guimarães, (2014).

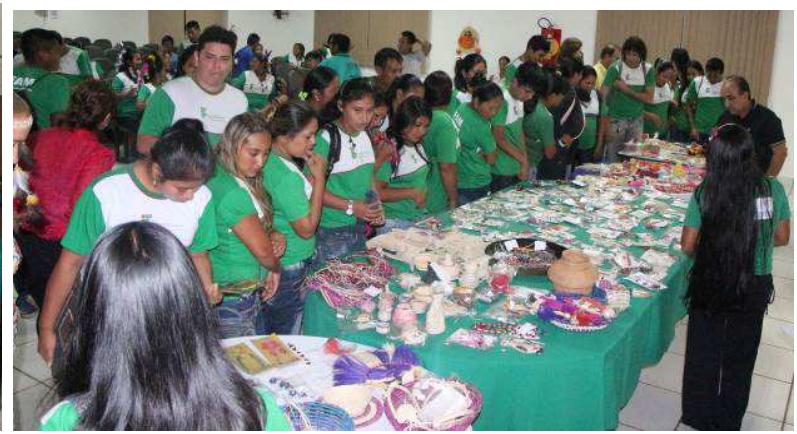

FIGURA 7 Exposição e negócios dos artigos indígenas

A cadeia produtiva do tucum - (CPT) ou também chamada cadeia de artigos indígenas de tucum compreende as etapas tradicionais de obtenção de fibras naturais, coleta, fiação, tecelagem, acabamento - adornos, sementes e acessórios da fauna (dentes e ossos de animais felinos e roedores, penas e bicos de aves, dentre outros). Esse processo ficou fartamente demonstrado, a partir da realização do presente trabalho, com foco na região do Alto rio Negro. A partir da matériaprima, a produção semi-industrial tornou a produção de artigos indígenas compensadora e desafiadora no mercado dos centros consumidores, o que assegura uma tecnologia social em caráter complementar aos saberes tradicionais locais, a serviço da cultura indígena.

O curso de qualificação artesanal foi ancorado no viés da formação inicial e continuada, aspecto que favoreceu às indígenas artesãs as diretrizes do acesso, permanência e êxito na formação profissional. A certificação no artesanato indígena, com o uso desta inovação tecnológica, alcançou o patamar de $100 \%$ dos participantes, sendo a evasão escolar uma prática não presente nessa formação. Em face do sucesso na formação profissional e para maximizar o andamento das atividades artesanais nas comunidades indígenas, as participantes do curso foram contempladas com os seguintes componentes: fiador de tucum à pedal com reversor (Tc-Pr), fiador de tucum motorizado com reversor (Tc-Mr), teares à pedal e penteliço.

Atualmente, as comunidades assistidas pelo programa de capacitação artesanal indígena oferecem produtos de qualidade e em quantidade para o mercado consumidor municipal e estadual, além da comercialização direta em feiras de exposição, oficinas e eventos turísticos, entre outros eventos artesanais. A qualidade dos produtos artesanais gerados com o auxílio desta tecnologia, foi atestada e certificada pelos consultores do SEBRAE, no momento da exposição artesanal realizada pelos discentes no encerramento das atividades do curso.

\section{CONCLUSÕES}

A tecnologia artesanal inserida na cadeia produtiva do tucum - (CPT) provocou maior competividade quanto aos preços, à quantidade e à qualidade dos artesanatos da espécie aqui abordada. Isso se deu a partir incorporação do uso de tecnologia social, que resultou na aceleração do processamento da matéria-prima e no aproveitamento na confecção de produtos artesanais, em todas fases produtivas, protagonizadas pelas mulheres indígenas envolvidas. 


\section{AGRADECIMENTOS}

Ao Instituto Federal do Amazonas, Campus São Gabriel da Cachoeira. Ao Pe. Bruno Bianchi pelo estímulo e apoio decisivo no desenvolvimento desse projeto.

\section{REFERÊNCIAS}

ALBINANTE, S. R.; PACHECO, E. B. A. V.; VISCONTE, L. L. Y. Revisão dos tratamentos químicos da fibra natural para mistura com poliolefinas. Quimica Nova, v.36, n.1, 114-122, $2013 . \quad$ Disponível em: <http://quimicanova.sbq.org.br/audiencia_pdf.asp?aid2=2908\&nomeArquivo=Vol36N 01_114_20-RV12008.pdf>. Acesso em: 14 jan. 2017.

ABREU, R. \& NUNES, N. L. Tecendo a tradição e valorizando o conhecimento tradicional na Amazônia: 0 caso da linha do tucum. Horizontes Antropológicos, Porto Alegre, ano 18, n. 38, p. 15-43, jul./dez. 2012. Disponível em: <http://dx.doi.org/10.1590/S0104-71832012000200002>. Acesso em: 16 jan. 2017.

CARDOSO, M. S. \& GONÇALEZ, J. C. Aproveitamento da casca do coco-verde (Cocos nucifera L.) para produção de poupa celulósica. Ciência Florestal, Santa Maria, v. 26, n. 1, p. 321-330, jan/mar., 2016. ISSN 0103-9954 321. DOI:10.5902/1980509821126. Disponível em: <http://www.scielo.br/pdf/cflo/v26n1/0103-9954-cflo-26-01-00321.pdf>. Acesso em: 14 jan. 2017.

CERCHIARO, R. M. Feira da Natividade Abre Espaço Para a Comercialização do Artesanato Brasileiro. Disponível em: $<\mathrm{http}: / / w w w$.artesanato.com/noticias/artesanato-brasileiro/feira-da-natividade-eartesanato-brasileiro>. Acesso em: 10 fev. 2016.

DIDONET, A. A. \& FERRAZ, I. D. K. O comércio de frutos de tucumã (Astrocaryum aculeatum G. Mey - ARECACEAE) nas feiras de Manaus (Amazonas Brasil). Revista Brasileira de Fruticultura, Jaboticabal - SP, v. 36, n. 2, p. 353-362, Junho 2014. Disponível em: <http://dx.doi.org/10.1590/0100-2945-108/13>. Acesso em: 14 jan. 2017.

FORTES, A. C. R.; OLIVEIRA, M. S. P; OLIVEIRA, N. P.; SANCHES, E. N. M.; CUNHA, E. F. M. Transferibilidade de locos microssatélites desenvolvidos em outras espécies de palmeiras para Astrocaryum vulgare Mart. Revista de Ciências Agrárias, v. $59, \quad$ n. $1, \quad$ p. 80-86, jan./mar. 2016. Disponível em: $<$ https://www.researchgate.net/profile/Elisa_Moura/publication/305694348_Transferib ilidade_de_locos_microssatelites_desenvolvidos_em_outras_especies_de_palmeira s_para_Astrocaryum_vulgare_Mart/links/57a493b808ae3f45292b2b3f.pdf $>$. http://doi.editoracubo.com.br/10.4322/rca.1844. Acesso em: 14 jan. 2017.

GUIMARÃES JUNIOR, M.; NOVACK, K. M.; BOTARO, V. R. Caracterização anatômica da fibra de bambu (Bambusa vulgaris) visando sua utilização em compósitos poliméricos. Revista Iberoamericana de Polímeros 11(7), 442-456 SLAP, $2010 . \quad$ Disponível em: <http://www.ehu.eus/reviberpol/pdf/DIC10/guimaraes.pdf>. Acesso em: 14 jan. 2017. 
MARTINEZ, N. T.; SCHIRIGATTI, E. L.; SILVA, J. C. G. Cadeia produtiva do artesanato por meio do Programa Ñandeva no Brasil voltado para o segmento turístico. Caderno Virtual de Turismo. Rio de Janeiro, v. 12, n. 3, p.309-322, dez. 2012.

Disponível

em: <http://www.ivt.coppe.ufr..br/caderno/index.php?journal=caderno\&page=article\&op=v iew\&path\%5B\%5D=685>. Acesso em: 14 jan. 2017.

MAXIMIANO, C. A. Mulheres Indígenas: Diálogo Sobre a Vida na Cidade. Ponto Urbe Revista do núcleo de antropologia urbana da USP 13 | 2013 Ponto Urbe 13. Disponível em: <file:///C:/Users/bvini/Downloads/pontourbe-672.pdf>. Acesso em: 14 fev. 2017.

MDIC. Ministério do Desenvolvimento, Indústria e Comércio Exterior. Disponível em:

$<$ http://www.desenvolvimento.gov.br/sitio/interna/noticia. php?area=4\&noticia=12281

>. Acesso em 13 de fev. de 2017.

OLIVEIRA, E. C.; VERDU, F. C.; REINERT, M.; Sustentabilidade por meio do comércio justo: o caso de uma cooperativa que produz artesanato em seda. Organizações e Sustentabilidade, Londrina, v. 2, n. 2, p. 114-149, jul./dez. 2014. Disponível em: <file:///C:/Users/bvini/Downloads/20497-106699-1-PB.pdf>. Acesso em: 1 fev. 2017.

PACHECO, K. M. M.; ORTUÑO, B. H.; MIRANDA, I. P. A.; NASCIMENTO, C. C.; PACHECO, A. S. Oportunidades e limitações do uso da fibra natural de tucumã-i (Astrocaryum acaule) para a gestão e desenvolvimento de produtos semi-industriais. 8 - Congresso Brasileiro de Gestão de Desenvolvimento de Produto - CBGDP 2011, 12, 13,14 DE SETEMBRO DE 2011, PORTO ALEGRE, RS - BRASIL. Disponível em: <http://labpalm.inpa.gov.br/arquivos/old/arq_pdf/Natural_fiber.pdf>. Acesso em: 7 fev. 2017.

PALMweb. 2016. Palmweb: Palms of the World Online. Disponível em: <http://www.palmweb.org >. Acesso em 20 de fevereiro de 2017.

SEBRAE. Projeto resgata identidade cultural de artesanato na fronteira. Boletim do empreendedor. Boletim mensal, n 53, Ano 3, Jun. 2010. Disponível em: $<$ http://www.sebraepr.com.br/portal/page/portal/Portal internet /Bempr_Index/bempr_artigo?_dad=portal\&_boletim $=13 \&$ filtro=243\&_artigo $=3531$ >. Acesso em: 10 fev. 2017.

SANTOS, K. K. M. P. \& SILVA, R. J. N. O uso dos recursos naturais do cerrado para produção artesanal: um estudo de caso entre os índios. Revista Nera - ano19,n. 33 -set/dez $2016 \quad-\quad$ ISSN: 1806-6755. Disponível em: <file:///C:/Users/bvini/Downloads/3109-16483-1-PB.pdf>. Acesso em: 14 fev. 2017.

SOENTGENA, J. \& HILBERTB, K. A química dos povos indígenas da américa do sul. Quimica Nova,v.39, n.9, 1141-1150, 2016. Disponível em: <http://dx.doi.org/10.21577/0100-4042.20160143>. Acesso em: 14 fev. 2017. 
TROMBINI, F. A realidade do artesão no Brasil. Disponível em: <http://www.webartigos.com/artigos/a-realidade-do-artesao-no-brasil/25744/>.

Acesso em: 14 fev. 2017. 